\title{
ONTOLOGIA DUSSELIANA: \\ UMA LEITURA POLÍTICO-PEDAGÓGICA PARA A EDUCAÇÃO AMBIENTAL CRÍTICA
}

\author{
ONTOLOGY DUSSELIANA: \\ READING FOR EDUCATIONAL POLICY-CRITICAL ENVIRONMENTAL \\ EDUCATION
}

\section{ONTOLOGÍA DUSSELIANA: \\ UNA LECTURA POLITICO-PEDAGÓGICA DE LA EDUCACIÓN AMBIENTAL CRÍTICA}

César Augusto Soares da COSTA ${ }^{1}$

RESUMO: Neste ensaio recuperamos alguns dos conceitos fundamentais da obra do filósofo argentino Enrique Dussel, visando a contribuir com formulações teóricas do pensamento latino americano para a educação ambiental crítica. Este pensador foi escolhido por ser uma indiscutível referência do pensamento latino-americano, sendo o principal expoente da Filosofia da Libertação, com larga influência não somente na educação, mas também nos movimentos sociais, na teologia da libertação e no pensamento filosófico e sociológico da América Latina. Logo, Dussel não é um autor ambientalista estritamente, mas sua concepção de mundo e a busca da emancipação humana e transformação social, auxiliam na práxis crítica educativa e na construção de novas formas de nos relacionarmos com/na natureza.

Palavras-chave: Enrique Dussel - Educação Ambiental Crítica - Filosofia da Libertação natureza.

\begin{abstract}
In this essay we recover some of the fundamental concepts of the work of the Argentinean philosopher Enrique Dussel, aiming to contribute to theoretical formulations of the Latin American thought for critical environmental education. This thinker was chosen to have an indisputable reference in Latin American thought and the main exponent of Liberation Philosophy, with wide influence not only in education but also in social movements, liberation theology and the philosophical and sociological thought of America Latina. Soon, Dussel is not strictly an environmentalist author, but his conception of the world and the pursuit of human emancipation and social transformation, assist in critical educational praxis and the construction of new ways of relating to / in nature.
\end{abstract}

Keywords: Enrique Dussel - Critical Environmental Education - Philosophy of Liberation nature.

\footnotetext{
${ }^{1}$ Sociólogo. Doutorando em Educação Ambiental/FURG. Pesquisador do Laboratório de Investigações em Educação, Ambiente e Sociedade-LIEAS/UFRJ. E-mail: csc193@ hotmail.com
} 
RESUMEN: En este ensayo nos recuperamos algunos de los conceptos fundamentales de la obra del filósofo argentino Enrique Dussel, con el objetivo de contribuir a las formulaciones teóricas del pensamiento latinoamericano para la educación ambiental crítica. Este pensador fue elegido para tener una referencia indiscutible en el pensamiento de América Latina y el principal exponente de la filosofía de la liberación, con gran influencia no sólo en la educación sino también en los movimientos sociales, la teología de la liberación y el pensamiento filosófico y sociológico de América Latina. Pronto, Dussel no es estrictamente un autor ambientalista, pero su concepción del mundo y la búsqueda de la emancipación humana y la transformación social, ayudar en la praxis educativa crítica y la construcción de nuevas formas de relacionarse con / en la naturaleza.

Palabras clave: Enrique Dussel - Educación Ambiental Crítico - Filosofía de la Liberación naturaleza.

\section{Colonialismo e ambientalismo na América Latina}

A reflexão que propusemos neste ensaio visa tratar das contribuições de Enrique Dussel à luz da Educação Ambiental (EA) crítica. Tal autor é um dos grandes ícones do pensamento revolucionário, filosófico e sociológico latino-americano. Entendemos que esse movimento de aproximação teórica é relevante, uma vez que temos atualmente uma grande quantidade de pesquisas em educação ambiental espalhadas em vários programas de pós-graduação e que reconhecem a diversidade social e cultural latino-americana não abdicando do trabalho de procurar os elos que unem os povos a partir da superação das relações sociais alienadas no capitalismo.

O ponto de partida deste texto é de que nossas sociedades estão em dívida com enormes parcelas da população condenadas a viverem em estados de "sub-emancipação". No mesmo sentido, várias práticas educativas ambientais supostamente voltadas para emancipação não estão inseridas numa trajetória de lutas sociais, que foram ignoradas, silenciadas ou esquecidas em nossa caminhada pedagógica. Constata-se que parte dos educadores e pesquisadores não se preocupa com a tarefa social da ciência num país de tantas exclusões, isto é, não dialetizam porque as políticas públicas obedecem mais a ética do mercado do que de um compromisso efetivo com o direito das pessoas, de modo a dar condições à dignidade humana (ANDREOLA, 2003). 
A lógica colonial, expressa-se pela distribuição desigual da riqueza, mas de maneira igual pelo domínio geopolítico da epistemologia. Está radicalizada desde o estabelecimento do sistema de classificação hierárquica em todas as esferas sociais até a supressão de economias e culturas existentes antes da chegada dos colonizadores (DUSSEL, 2000). Negar as origens das civilizações estabelecidas antes da colonização é como uma maldição que atravessa a história da América Latina, pois seus efeitos se manifestam no critério de inferioridade de povos sem história e de Estados sem nação. Ou seja, os colonizados como forma de resistência, aprenderam a cultura dos dominadores, tanto no campo da atividade material quanto da prática religiosa que engendrava uma subjetividade colonizada. Dentro desta perspectiva, colonialidade e independências colocam-se de forma igual, ou seja, a proposta descolonial dos povos indígenas e afrodescendentes não foram contempladas pela emancipação política (STRECK, ADAMS, MORETTI, 2010).

Levando em conta os aspectos acima, compartilhamos da necessidade de uma visão filosófico-pedagógica em Enrique Dussel perante a questão ambiental, uma vez que, a colonialidade nas causas sociais, políticas e econômicas impedem o ser humano de ser-mais pelo modo de produção capitalista. A relevância das reflexões de Dussel para a educação ambiental crítica consiste em considerar o sofrimento do outro a consequência de uma realidade escondida em que sujeitos subjugam outros (entendidos como inumanos, inferiores, não civilizados, por meio de relações desiguais e opressivas de poder). Consequentemente, sua Ética da Libertação objetiva refletir sobre a relação entre o eu e o outro no campo social, debatendo a questão da exclusão social. A partir disso, analisa criticamente o discurso eurocêntrico moderno e a possibilidade de superação do irracionalismo moderno por meio da razão crítico-libertadora. Dussel está para além de uma mera reflexão racional de constatação da negação do sujeito humano porque se constitui em uma ética crítica, ou seja, "da transformação como possibilidade da reprodução da vida da vítima e como desenvolvimento factível da vida humana em geral”. (DUSSEL, 2000, p. 564). Nisso consiste o postulado essencial fundamental da sua Filosofia da Libertação.

\section{Perspectiva política e o sentido da libertação em Dussel}

Convém neste momento, apontar o que Dussel entende ao sentido e significado político do termo "libertação", mas antes de tudo, também tornando clara a visão do autor acerca dos seus principais postulados que orienta as sua perspectiva. Em Dussel, a antinomia alienação- libertação frente à Educação Ambiental. No entendimento de Dussel: 
Até muito recentemente a política não tinha descoberto sua responsabilidade ecológica [...] A previsão de permanência da vida da população de cada nação na humanidade que habita o planeta Terra é primeira e essencial função da política [...] Uma humanidade extinta obviamente aniquilaria o campo político e todos seus sistemas possíveis (2007, p. 64).

Sendo assim, consideramos que a abordagem ambiental na América Latina (AL) não é algo recente (PORTO-GONÇALVES, 2012), embora careça de sistematizações maiores, bem como de uma crítica mais consistente dos seus problemas. Uma abordagem da questão ambiental a partir da América Latina não pode ignorar esse contexto em que se dá a institucionalização dessa problemática no período que se abre desde os anos 1970, havendo uma contribuição específica na região a esse debate teórico-político. A crítica à sociedade capitalista (consumismo/produtivismo) foi acompanhada pelo respeito aos povos, países e regiões cujas populações viviam em condições subumanas e não consumiam o mínimo necessário à sua existência. $\mathrm{O}$ debate acerca da natureza do desenvolvimento foi impulsionado e nele a reflexão sociológica de Celso Furtado teve relevância ao problematizar a ideia. Também Josué de Castro se ligou a questão oferecendo um artigo sob o título Subdesenvolvimento: causa primeira da poluição, redigido em 1972, às vésperas da Conferência de Estocolmo (CASTRO, 2003).

Segundo Porto-Gonçalves (2012, p. 26-27):

Muito embora correntes hegemônicas da esquerda marxista tivessem, de início, criticado o ecologismo, o fato é que diferentes movimentos sociais, sobretudo na América Latina, começaram a assimilar a questão ambiental à sua agenda política. Junto com esses movimentos se desenvolveram importantes correntes teóricopolíticas no campo ambiental: a "ecologia popular", o "ecologismo dos pobres" e o eco-socialismo - onde se destacaram intelectuais como o líder seringueiro Chico Mendes, assim como o epistemólogo mexicano Enrique Leff, o economista catalão Joan Martinez Alier que tem fortes ligações com movimentos sociais latinoamericanos, o antropólogo colombiano Arturo Escobar, o biólogo e antropólogo mexicano Victor Toledo, o sociólogo marxista brasileiro Michel Löwy, entre tantos. Essa contribuição teórica-política é tão importante para compreender os complexos processos sócio-históricos que estão curso como são, ainda hoje, as teses de José Carlos Mariátegui elaboradas nos anos vinte do século passado, a Teoria da Dependência, sobretudo em sua vertente marxista (Rui Mauro Marini e Theotonio dos Santos), a Pedagogia do Oprimido (Paulo Freire), a Teologia da Libertação (Frei Beto, Leonardo Boff, Enrique Dussel), assim como o Pensamento Descolonial (desde Franz Fanon e Aimé Cesaire, ambos caribenhos, até o mexicano Pablo González Casanova, a aymara-boliviana Silvia Rivera Cusicanqui e o peruano Aníbal Quijano).

Os marcos teóricos da Filosofia da Libertação de Enrique Dussel podem assim ser aclarados:

a experiência inicial da Filosofia da Libertação consiste em descobrir o "fato" opressivo da dominação, em que sujeitos se constituem "senhores" de outros sujeitos, no plano mundial (desde o início da expansão europeia em 1492; fato constitutivo que deu origem à "Modernidade"), Centro-Periferia; no plano nacional 
(elites-massas, burguesia nacional-classe operária e povo); no plano erótico (homem-mulher); no plano pedagógico (cultura imperial, elitista, versus cultura periférica, popular, etc.); no plano religioso (o fetichismo em todos os níveis), etc. (DUSSEL, 1995, p. 18) (...). Por meio de sua Filosofia da Libertação analisa o processo opressivo da dominação, em que uns se tornam senhores de outros no plano mundial, questionando o discurso da modernidade. Tanto a sua filosofia quanto a sua Ética da Libertação possuem clara opção política pelas vítimas do sistema-mundo, compreendido como o processo de ampliação da influência cultural de um sistema inter-regional (alta cultura ou sistema civilizatório) a outras culturas. (OLIVEIRA E DIAS, 2012, p. 92).

Aqui se faz necessário, trazermos a contribuição dusseliana ao sentido e significado do termo libertação. Segundo Dussel (DUSSEL, 1986), a Filosofia latino-americana terá sua originalidade ao se fundar sobre um projeto ético-antropológico interpretante do homem latino-americano. Tal projeto só poderá ser realizado se se constituir numa filosofia sobre novas bases metodológicas e históricas, sendo necessário ao pensamento latino-americano ultrapassar os modelos metodológicos das filosofias européias que geram a alienação do homem latino-americano (OLIVEIRA, s/d).

No plano metodológico, Dussel, partindo de Marx e da tradição semita propõe uma nova formulação metodológica: o Método anadialético. Trata-se de uma metodologia filosófica original, porque se distingue e supera os procedimentos e categorias etnocêntricas da modernidade européia. O Método da Filosofia da Libertação terá seu ponto de partida no princípio da alteridade, onde o pressuposto desse método estabelece que o discurso filosófico tenha um caráter eminentemente ético, para além da dimensão puramente lógica. O discurso é válido ou inválido não pôr sua correção lógica, mas por seu acordo ou desacordo com a justiça (DUSSEL, 1986). Torna-se evidente que neste ensaio, pretendemos desenvolver seus principais postulados a partir das categorias alienação e libertação e suas implicações para a questão ambiental.

Para Dussel, a alienação consiste no fato de tomar o "outro enquanto instrumento" (objeto prático), isto é, enquanto um ser que serve de mediação para a realização das vontades do outro, aniquilando a semelhança e a distinção. Assim, a alienação resulta de uma práxis de dominação, que é a afirmação de um projeto totalizador opressor e autoritário (OLIVEIRA, s/d). Nessa perspectiva o projeto dominante impõe seu horizonte de abrangência, utilizando e instrumentalizando a tudo e a todos em função de uma cultura individualista, como por exemplo, expressa o capitalismo. Para assegurar a realização desse projeto dominador seus interessados promovem diversos tipos de alienação, a do capital, do trabalho, da cultura, a política, a religiosa, a educativa. Deve-se observar, segundo Dussel, que a alienação 
apresenta-se não somente em forma de discurso, mas também, ao nível das ações e condutas (DUSSEL, 1977).

A libertação dentro deste horizonte consiste na desalienação das pessoas, povos, culturas e instauração de uma nova ordem fundada no respeito à alteridade e exterioridade humana, pois no processo de desalienação é preciso estar atento para não compreender o outro apenas como dimensão objetiva do mundo, como um meio para realizar determinado "projeto libertador". A partir daí, somos provocados a buscar relações fraternas e solidárias que nos motiva à subversão do sistema para reconstruí-lo numa justiça real que afirma a dignidade humana. Sendo assim, indicamos que:

\begin{abstract}
A metodologia de investigação da Filosofia da Libertação poderá revigorar os estudos de história latinoamericana na direção em que estamos apontado, superando a perspectiva historiográfica eurocêntrica. O método ana-dialético de Enrique Dussel poderá expor a totalidade histórica a partir das múltiplas configurações culturais vividas dinamicamente pelas etnias e grupos sociais, cujo ethos jamais está absolutamente incluído no projeto de dominação das classes colonizadoras (OLIVEIRA, s/d, p. 22)
\end{abstract}

Nesta perspectiva, o método analético de Dussel, é um método cujo ponto de partida é uma opção ética e uma práxis histórica concreta. Evidencia-se que deve aliar o rigor teórico especulativo e a ação ético-política à favor da libertação humana, uma vez que, a indiferença compactua com o sistema vigente. Pois não é pela lógica e a eficácia que devemos mensurar o conhecimento, mas pelo seu caráter humanizador e justo das relações sociais, sobretudo, nas relações com a natureza. Ou seja, para Dussel é através da Ética da Libertação com seus princípios mais elaborados que traz em seu horizonte uma ética necessária em face da "miséria que aniquila a maioria da humanidade no final do século XX", junto com a incontível e destrutiva contaminação ecológica do planeta Terra (DUSSEL, 2000, p. 15).

Sua ética fundamenta-se também na criticidade que entendemos ser vital para a perspectiva ambiental assumida neste ensaio. Significa que sua razão crítica "permite o (auto) reconhecimento das vítimas do sistema-mundo (dominados: operários, índios, escravos, etc. e discriminados: mulheres, idosos, incapacitados, imigrantes, etc.), bem como o descobrimento de suas alteridades e autonomias, negadas pelo sistema-mundo vigente" (OLIVEIRA E DIAS, 2012, p. 98). 


\section{Contribuições de Enrique Dussel à Educação Ambiental Crítica}

A proposta de Dussel para a Educação Ambiental crítica auxilia na adoção de estratégias políticas dirigidas à emancipação/libertação inscritas nos marcos de um processo de radicalização da questão social, sendo contrários a lógicas neoliberais hegemônicas, próprias da feição que o capitalismo assume na AL em sua matriz colonial. É evidente que a filosofia Dusseliana, não pode ser tratada como uma filosofia educacional, muito menos ambiental, haja vista, que em seus escritos, não prevalece uma intenção pedagógica (embora seja um conceito no escopo de seu pensamento). Apontamos que o pensador latino-americano tematizou um pensamento filosófico-político que na história da América Latina e na história da educação tiveram expressiva influência nas pedagogias críticas e nos instrumentaliza para refletirmos criticamente a sociedade, bem como o contraponto à efetivação dos projetos societários vigentes que excluem o ser humano da possibilidade de vir-à-ser mais (ZITKOSKI, 2007).

Em Dussel, constatamos a preocupação fundamental com a Libertação dos sujeitos envolvido no processo de opressão do sistema colonial europeu, cujo processo deixou chagas sociais em nosso continente. Desse modo, o autor nos propõe refletir sobre a nossa condição de sujeitos inseridos na realidade social, para que possamos desenvolver uma perspectiva crítica dos acontecimentos sociais, políticos, culturais e econômicos em torno do sistema vigente. A abordagem latino-americana de Enrique Dussel descobre sua vitalidade e alcance crítico neste esforço de diálogo e aproximação com a questão ambiental, pois através desta perspectiva somos capazes de descobrir um aspecto fundamental: a existência de muitos mundos diferentes dentro do nosso mundo: a "outridade latino-americana" (DUSSEL, 1986), dentro da nossa realidade. Metodologicamente optamos por valorizar o foco de análise na educação trazendo o enfoque da filosofia e da educação libertadora, por reconhecermos a importância que ela ocupa, enquanto práxis, orientação e efetividade histórica em nosso continente (COSTA, 2011).

A Filosofia da Libertação de Enrique Dussel se apresenta num propósito único: libertar filosófico-politicamente (DUSSEL, 1986). Ou seja, quer libertar-nos politicamente, mostrando-nos alguns mecanismos de dominação e exploração que normalmente nos passam despercebidos ao cotidiano. A libertação filosófica e a libertação política se completam e são inseparáveis no método dusseliano, pois contemplam todas as dimensões da vida pessoal e coletiva. Assim, possibilitam-nos instrumentos teórico-práxicos para libertação integral, não 
só como sujeitos, mas enquanto sociedade, impelindo-nos a uma nova ordem social justa e igualitária. O apelo à "responsabilidade do outro" e "pelo próximo", que este rosto (Outro) traz está concretamente, existencialmente e historicamente marcado.

O "outro", de quem assinala Dussel, é o outro com um rosto, o outro concreto, em milhões de rostos que carregam as marcas do sangue, os sulcos da fome e da humilhação. Esta crítica, o autor não faz no nível das argumentações metafísicas, mas sim no plano humano das opressões historicamente estabelecidas. Em outras palavras, poderíamos falar numa ética da libertação como fundamentação ética e radical para a realização humana (DUSSEL, 1986). O "outro" negado de Dussel é, nesse contexto, o oprimido que assinala Freire, uma vez que, o mesmo sempre buscou uma práxis dentro de seu país, sendo incontestável que o "oprimido" (que mencionava em seus escritos) significa o encobrimento de todos os povos da América Latina $^{2}$ (DUSSEL, 1993). A devida e necessária aproximação entre exclusão latino-americana e reconhecimento da solidariedade humana como ponto de partida para uma redefinição do atual projeto societário, requer em ancorar neste método de abordagem na realidade visando transformá-la radicalmente. Tal abordagem envolve compreensões da questão ambiental fruto de sistema colonizador e dominante que por séculos alija o povo latino-americano de sua realização (ASSMANN E SUNG, 2000).

\section{Considerações Finais}

À luz do que foi explicitado, indicamos que a relevância dos referenciais e categorias trabalhados por Enrique Dussel para a EA crítica, contribuem, uma vez que, para a perspectiva crítica que o pensador argentino está inserido, a práxis de dominação não reconhece a alteridade. O outro deixa de ser importante para tornar-se coisa. O agir da opressão, ao negar o Outro como outro, incorpora-o num sistema que o aliena e a possibilidade em transformarmos as formas como nos relacionamos com a natureza, o que implica, nos relacionarmos com a humanidade. Seguindo o viés marxista, para Dussel a práxis de dominação na organização da produção é o que define o grau de alienação na formação

\footnotetext{
${ }^{2} \mathrm{Na}$ crítica histórica de Zanotelli, há o seguinte questionamento: Quais são estes traços identitários? Somos latino-americanos? Se o somos, não aceitamos facilmente que o sejamos segundo a visão preconceituosa que os países do Primeiro Mundo têm de nós. Mas o fato de sermos tratados preconceituosamente, estigmatizados como indolentes, preguiçosos, andarilhos, improvisadores, não muito sérios em cumprir os compromissos empenhados, etc... de não termos nem espaço, voz e vez nos meios de comunicação daqueles países, o fato ainda de sermos esquecidos e negados, mesmo e especialmente nos fatos em que somos lembrados (carnaval, futebol e escândalos) essa contraposição, essa discriminação, é também um lugar de nossa identificação. É preciso recolher com cuidado os vetores de nossa identidade e o processo de nossa identificação. ZANOTELLI, J. América Latina: raízes sócio-político-culturais, p. 14.
} 
social. No modo de produção assim constituído, o Outro (trabalhador) perde sua liberdade. Sua vida e seu fazer já não lhe pertencem e passa a ser instrumento a serviço de interesses alheios. Alienação e dominação são aspectos intrínsecos à totalidade totalizada.

Segundo Dussel, a libertação que implica num trabalho em favor do Outro, não pode ser resumido na relação homem-homem (práxis), mas inclui a relação homem-natureza (poiesis). Logo, o sentido da práxis de libertação será de transposição do horizonte do sistema para construir uma formação social nova e mais justa. Tal posição vem apontar que:

A exclusão social se constitui num problema ético e político, o que implica, a partir do olhar de Dussel, não apenas reconhecer a existência de vítimas ou de oprimidos ou de abstrair conceitos e valores que reforçam a solidariedade, a justiça social, os direitos humanos, mas há necessidade de se problematizar as causas da exclusão a partir do reconhecimento do outro não só como excluído, mas também como sujeito, assumindo-se um compromisso ético com o outro, denunciando a exclusão e se apontando perspectivas de mudança (OLIVEIRA E DIAS, 2012, p. 105).

É neste horizonte que o pensamento de Enrique Dussel possui reconhecimento em suas premissas políticas que se tornam essenciais para a EA crítica. Consideramos que a Educação Ambiental é dimensão da educação, é atividade intencional da prática social, que imprime ao desenvolvimento individual um caráter social em sua relação com a natureza e com os outros seres humanos, com o objetivo de potencializar essa atividade humana, tornando-a mais plena de prática social e de ética ambiental (TOZONI-REIS, 2004). Em síntese, compreendemos que a posição de Dussel contribui de forma decisiva com a questão ambiental na forma de repensarmos os fundamentos e a práxis de uma Educação Ambiental consistente no enfrentamento da realidade de desigualdade social da América Latina e no compromisso social manifestado no processo pedagógico emancipatório. Com este autor crítico, aprendemos "que a consciência ético-crítica é necessária para que se compreendam as causas da opressão e da exclusão sociais para intervir e transformar as realidades educacional e social" (OLIVEIRA E DIAS, 2012, p. 105).

\section{REFERÊNCIAS BIBLIOGRÁFICAS}

ANDREOLA, B. Ética e solidariedade planetária. In: DALLA VECHIA, A. (Org.). Ética: diversidade e diálogo na produção de referências para a educação. Pelotas: Seiva, 2003, p. 1737.

Freire e Habermas: aproximações possíveis e convergências impossíveis. s/d.

ASSMANN, Hugo; SUNG, Jung Mo. Competência e sensibilidade solidária. Petrópolis: Vozes, 2000. 
BOUFLEUER, P. Pedagogia latino-americana: Freire e Dussel. Ijuí: UNIJUÍ, 1991.

CASTRO, Josué de. Subdesenvolvimento: causa primeira da poluição In: CASTRO, Josué de. Fome: um tema proibido. Rio de Janeiro: Civilização Brasileira, 2003.

DUSSEL, E. 20 teses de política. Buenos Aires: CLACSO; São Paulo: Expressão Popular, 2007.

DUSSEL, E. Ética da Libertação na idade da globalização e da exclusão. Petrópolis: Vozes, 2000.

. Método para uma Filosofia da Libertação. São Paulo: Loyola, 1986.

. Filosofia da Libertação. São Paulo: Loyola, 1977.

. 1492: o encobrimento do Outro: a origem do mito da modernidade: Conferências de

Frankfurt. Petrópolis: Vozes, 1993.

. Filosofia da Libertação: crítica à ideologia da exclusão. São Paulo: Paulus, 1995.

FANON, F. Os condenados da Terra. Rio de Janeiro: Civilização Brasileira, 1979.

FREIRE, P. Pedagogia do Oprimido. Rio de Janeiro: Paz e Terra, 1983.

. Pedagogia da Esperança. Rio de Janeiro: Paz e Terra, 1994.

. A sombra desta mangueira. São Paulo: Olho d'água, 1995.

FREIRE, P; FAUNDEZ, A. Por uma pedagogia da pergunta. Rio de Janeiro: Paz e Terra, 1995.

GHIGGI, G; KAVAYA, M. Frantz Fanon e a pedagogia da “colaboração muscular”. In:

STRECK, D. (Org.). Pensamento pedagógico latino-americano. Belo Horizonte: Autêntica, 2010. p. 377-391.

OLIVEIRA, D. O método da Filosofia da Libertação, segundo Enrique Dussel. s/d.

PORTO-GONÇALVES, C. W. A Ecologia política na América Latina: reapropriação social da natureza e reinvenção dos territórios. Santa Catarina, Interthesis, v. 9, n.1, 2012, p. 16-50.

OLIVEIRA, I; DIAS, A. Ética da libertação de Enrique Dussel: caminho de superação do irracionalismo moderno e da exclusão social. Caxias do Sul, Conjectura, v. 17, n. 3, p. 90106, set./dez. 2012.

PERALTA, J; RUIZ, J. Educação popular ambiental. Para uma pedagogia da apropriação do ambiente. In: LEFF, E. (Coord.). A complexidade ambiental. São Paulo: Cortez, 2004. p. 241280.

STRECK, D. (Org.). Pensamento pedagógico latino-americano. Belo Horizonte: Autêntica, 2010.

. Paulo Freire e a consolidação do pensamento pedagógico na América Latina. In:

STRECK, D. (Org.). Pensamento pedagógico latino-americano. Belo Horizonte: Autêntica, 2010. p. 329-345.

STRECK, D; ADAMS, T; MORETTI, C. Pensamento pedagógico em nossa América: uma introdução. In: STRECK, D. (Org.). Pensamento pedagógico latino-americano. Belo Horizonte: Autêntica, 2010. p. 19-35.

TOZONI-REIS, Marília. Educação ambiental: natureza, razão e história. Campinas, São Paulo: Autores Associados, 2004. 
Temas ambientais como "temas geradores": contribuições para uma metodologia ambiental, crítica, transformadora e emancipatória. Educar, Curitiba, n. 27, 2006. p. 93-110. ZANOTELLI, J. América Latina: raízes sócio-político-culturais. 3 ed. Pelotas: Educat: 2007.

ZITKOSKI, J. A Pedagogia freireana e suas bases filosóficas. In: GHIGGI, Gomercindo, SILVEIRA, Fabiane; PITANO, Sandro. (Orgs.). Leituras de Paulo Freire. Pelotas: Seiva, 2007. p. 229-248. 